\title{
Using Social Media as a Tool for Improving Academic Performance through Collaborative Learning in Malaysian Higher Education
}

\author{
Waleed Mugahed Al-rahmi ${ }^{1}$, Mohd Shahizan Othman ${ }^{1}$, Lizawati Mi Yusof ${ }^{1} \&$ Mahdi Alhaji Musa ${ }^{1}$ \\ ${ }^{1}$ Department of Information System, Universiti Teknologi Malaysia, Johor Bahru, Malaysia \\ Correspondence: Waleed Mugahed Al-rahmi, Faculty of Computing, Universiti Teknologi Malaysia, 81310 \\ UTM, Johor Bahru, Malaysia. E-mail: abumunir82@yahoo.com
}

\author{
Received: June 3, 2014 Accepted: January 16, 2015 Online Published: February 25, 2015 \\ doi:10.5539/res.v7n3p265 URL: http://dx.doi.org/10.5539/res.v7n3p265
}

\begin{abstract}
Nowadays, many higher education institutions are still depending on the traditionally-based learning management systems that actually do not use full capabilities of social media in engaging researchers in collaborative learning. Due to recent rise in social media usage, especially among researchers and lecturers of educational institutions, a great deal of research was conducted to explore how to take advantage of social media and use it to improve the researchers 'academic performance through collaborative learning. To achieve this objective, it is important to explore the actual relationship between two variables: social media and academic performance. This study is aimed at examining the relationship between using social media and improving academic performance. A survey was conducted among the research students of Universiti Teknologi Malaysia, and 323 valid responses were received. Structural equation modeling was employed to test the relationship between three constructs: social media, collaborative learning, and academic performance. The results showed a significant effect of social media on the students' academic performance with collaborative learning as the mediating variable. Without good collaborative learning, an education institution cannot take advantage of social media for improving academic performance.
\end{abstract}

Keywords: social media interactively, collaborative learning, academic performance, higher education, structural equation modeling

\section{Introduction}

Instead of being merely information consumers, web users have become joint-creators of social information in relation to the surge in social media (SM).Social media is also being more and more used to provide learning activities apart from its extensive use for social communications among the younger generation. The advent of web 2.0 is a result of the numerous efforts that were undertaken to integrate social media into the students' entire learning ecology. The implementation of social media in learning or education where learners are given the power to produce and arrange their own learning activities is behind the concept of E-learning 2.0 (Fredricks, 2002).

Practically, many higher education institutions are still depending on the traditionally-based learning management systems (LMS), which actually do not use full capacity of social media for improving global participation of students in learning through collaborative learning (CL) in social environment (Dabbagh \& Kitsantas, 2011). Based on a study conducted by (Dabbagh \& Kitsantas, 2011), the advent of web 2.0 has caused collaborating technologies to become mode of learning, especially for young generations; however, not many young learners take the advantages of social media in their academic performance (AP). In addition, (Greenhow, 2009) stated that a lot of learners do not actually understand the relationship between social media and their learning capabilities.

Based on the background presented above, the researcher believes that, using empirical analysis, it is necessary to address this gap by exploring the nature and extend of the relationship between social media and academic performance through collaborative learning. We propose a conceptual framework based on literature review and posit that social media positively affects academic performance. To verify the model, we conduct a survey among postgraduate students of Universiti Teknologi Malaysia using an adopted questionnaire. In this study, a quantitative approach is applied and the reliability and validity of the scales were tested. In this paper, due to wide scope of higher education, we extended the study previously-conducted by ( $\mathrm{Li}, 2012)$ who attempted to 
find out the relationship between social media and collaborative learning. The rest of the paper is organized as follows. Section 2 describes the hypotheses derived from literature review. Section 3 describes the methodology used in this research, including sampling technique and measurement. Section 4 discuses the results of data analysis obtained from structural equation modeling. Finally, Section 5 concludes the paper, presents limitations, and gives suggestions for future research.

\section{Social Media Interactively in Context of Academics}

A topic of interest for numerous researchers in education and social science is using and taking advantages of social media. Literature consists of useful ideas about employing social media in higher education (Hamid et al., 2009). Communication among learners and between them and their communities is improved through the use of social media. Facebook is one example where academicians can use social media in diverse styles; it can be considered as a way of communication for students to exchange information (Mack, Behler, Roberts, \& Rimland, 2007). The use of social media among students has steadily grown from 2007 to 2010 and the difference between the older and younger students usage of social media is reducing (Smith \& Caruso, 2010). A noted area of investigation for educationists and social scientists is the utilization of the social media by university students. (Hamid et al., 2009) believed that literature consists of useful designs and ways to use social media at postgraduate level.

Through social media use, students understand how to share, communicate, collaborate and socialize information and knowledge. Therefore, there are different advantages in the use of social media in higher education. To improve the students' learning experiences requires the use of social media in higher education. The effort and duration that students put into education-based activities are both represented by the students' involvement (Kuh, Kinzie, Cruce, Shoup, \& Gonyea, 2007). Also, previous studies proposed social media as an extremely influential tool for student learning and creating values; thus, this is educationally useful and it can help to reinforce academic expectations (Kuh, Kinzie, Cruce, Shoup, \& Gonyea, 2007). The main advantages of social media in teaching and learning contexts will be achievable once there is more awareness on how to utilize the social nature of these media. With an increased awareness, however, disengaged students can be encouraged to cooperate in educationally useful ways with their distinguished peers and trainers so that all students can achieve success through it (Rutherford, 2010). Certainly, there are prospective benefits to institutions that use social media to connect with current and prospective students (Kaya, 2010). However, the rapid pace of this change has caused many institutions not to establish necessary guidelines for use of social media before beginning to use the applications (Chickering \& Gamson, 1987).

\subsection{Research Hypothesis}

\subsubsection{Social Media Interactively and Academic Performance}

In the past several years, many articles have been published on the capability of social network tools in improving the students' learning abilities (Alexander, 2006; Nachmias, 2002; Wesch, 2009; Reuben, 2008; McDonald, 2009; Brainard, Oradini, \& Saunders, 2008; Thompson, 2008; Minocha, 2009). Some learning-related advantages of the use of social media in education context are as follow: enhancing the autonomous learning abilities, overcoming difficulties, cooperation, contemplative learning, fast/prompt feedback from instructors, decreasing the effect of geographical distances, clarity of students' effort, and the establishment of social dealings between academicians and students.

The current models of education that consider teacher as an initiator of education rather than propagator of information are compatible to the notion of utilizing Web 2.0 tools to improve knowledge and exchange information in educational situations. Students' dynamic involvement in learning, where they rebuild information/ideas based on their prior and current knowledge, adopts them as a part of the learning process; this idea is highlighted by the constructivist learning theories (Skemp, 1971; Papert, 1980; Siemens, 2004).

For instance, constructivism that asserts "learning happens when learners dynamically form their own knowledge by attempting to figure out (their learning environment)" (Mayer, 2008) appears particularly compatible with the utilization of social media for gaining knowledge. One of the most significant contributions of social networks to the education context is the prospect of knowledge sharing of students and their capability in using this knowledge along the social networks to overcome their problems and difficulties (Mason \& Rennie, 2008).

In an educational social network, in addition to the opportunity provided for teachers to create new contents and answer their students' questions, learners have a chance to contribute to the collective learning experience as a result of sharing knowledge through a social network in which the students also can create and share their 
knowledge. Still, there are some disapprovals and apprehensions concerning the validity, trust, and dependability of the content created by students in a social network (Jmora, 2010). According to Marianne (2010), using social media, the students professed that they experienced an improvement in their critical thinking skills and written communication skills, and they became more aware of their field of study, hence an improvement in their academic performance. Reading the classmates' remarks helps students achieve deeper insight into their subjects (McGarry, 2010). Based on the above discussion, we hypothesized as follows:

H1: There's a significant relationship between social media and academic performance.

\subsubsection{Social Media Interactively and Collaborative Learning}

Some recently-conducted studies highlight how web technologies and social media are used by academics; for instance, where academicians explicitly target blogs and wikis for their benefits. Their competency to promote interaction and cooperation between students of the same level across academic borders and non-academicians is one of the most well-known advantages of social media (Collins \& Hide, 2010; Rowlands, Nicholas, Russell, Canty, \& Watkinson, 2011; Al-rahmi \& Othman, 2013). Another frequently-mentioned advantage of social media is its use in keeping up the users with current research. For instance, an analysis of 10 science blog users discovered that apart from regularly reading scientific blogs written by their peers, they were also writing their own blogs simultaneously (Bonetta, 2007).

Social interactions support current relationships, and this helps to form relationships with academicians of the similar research area (Gruzd, Wellman, \& Takhteyev, 2011). The competency of disseminating the knowledge and information is another well-recognized advantage of using social media. For instance, contents related to academic fields are spread by blogging devises employed by numerous academicians (Bukvova, Kalb, \& Schoop, 2010; Luzon, 2009). Some of the advantages stated by academic bloggers include the ability to search for unanswered questions in more informal conditions, discovering a formidable ability by web writing, and having an area to deliberate issues in an exposed and public arrangement (Kirkup, 2010). Information dissemination was reported by Scholarly Twitter users as one of the main advantages of this social media, which has been shown very well-known during academia-based meetings (Letierce, Passant, Breslin, \& Decker, 2010; Al-rahmi et al, 2014; Ross, Terras, Warwick, \& Welsh, 2011). Students are motivated to cooperate more dynamically during class through collaborations among the teachers and students and they are encouraged to create an effective involvement with the topic substance (Gallini \& Moely, 2003; Kay \& LeSage, 2009). Therefore, based on the earlier discussion, we take into account that social media has a positive influence on collaborative learning, hence hypothesizing that:

H2: There's a significant relationship between social media and collaborative learning.

\subsubsection{Collaborative Learning and Academic Performance}

Collaborative learning, which happens when students collaborate in small units with a shared target, developing meanings, researching a subject or enhancing proficiencies are of the most advantageous aspects of active learning (Prince, 2004). An idea of learning that includes sharing information, know-hows, and authority, in which students coach and acquire knowledge from one another and nurture a beneficial dependence between one another, is referred to as collaborative learning (Panitz, 1996). This motivates students to involve in presenting the solution, clarifying as well as qualifying their views (Lantz, 2010), and enhancing the potential to reason analytically (Angeli, Valanides, \& Bonk, 2003; Garrison, Anderson, \& Archer, 2001). In such a context, students collaborate in the conception of their own knowledge and convert themselves into dynamic representatives in their knowledge acquiring process. So, this technique permits students to gain a deep insight into the content and aids them to form new knowledge from prior information (Draper, Cargill, \& Cutts, 2002; Kennedy \& Cuts, 2005). Student participation, fulfillment, commitment, and advanced-level learning are some of the positive results of collaborative learning (Hiltz, Coppola, Rotter, \& Turoff, 2000; Khan, 2000; Prince, 2004). Furthermore, collaborative learning provides the same chance for all involved students to understand the subject contents (Soller, 2001).

As dynamic collaborative learning is associated with the use of technology, the impact of active collaborative learning on the student's achievement is increased more (Stowell \& Nelson, 2007). This opinion is supported by Kryder (1999), stating that students are more cooperative in their learning process when they use technologies. Likewise, students who are expert in technology have a knowledge aptitude that is sensorial as well as visual and $80 \%$ of them are dynamic learners (Fowler, Armarego, \& Allen, 2001). A growing number of studies have focused on increasing the technology usage to encourage collaborative learning (Resta \& Laferrière, 2007), which indicates that technology has the ability to improve learning methods (Kreijns, Kirschner, \& Jochems, 2003).According to (Caldwell, 2007; Ribbens, 2007) believe that social media allows students to mentally 
compute questions put forward by the instructor as well as to enhance their involvement in learning process. Furthermore, social media encourages the creation of new ideas and their incorporation with the knowledge already gained (Mayer et al., 2009) and, through presenting significant alterations in the class format, motivates students to view the notions analytically(Guthrie \& Wigfield, 2000). Social media enables students to enhance their contribution to knowledge creation and develop their active learning (Guthrie \& Carlin, 2004; Thalheimer, 2003). The collaborations made by the students along the learning process, which improves their involvement in the subject matter and their performance as a whole, is achieved through social media (Ryan, 2000; Yourstone, Kraye, \& Albaum, 2008). Based on the above-mentioned issues, we suggest the following hypothesis:

H3: There's a significant relationship between collaborative learning and academic performance.

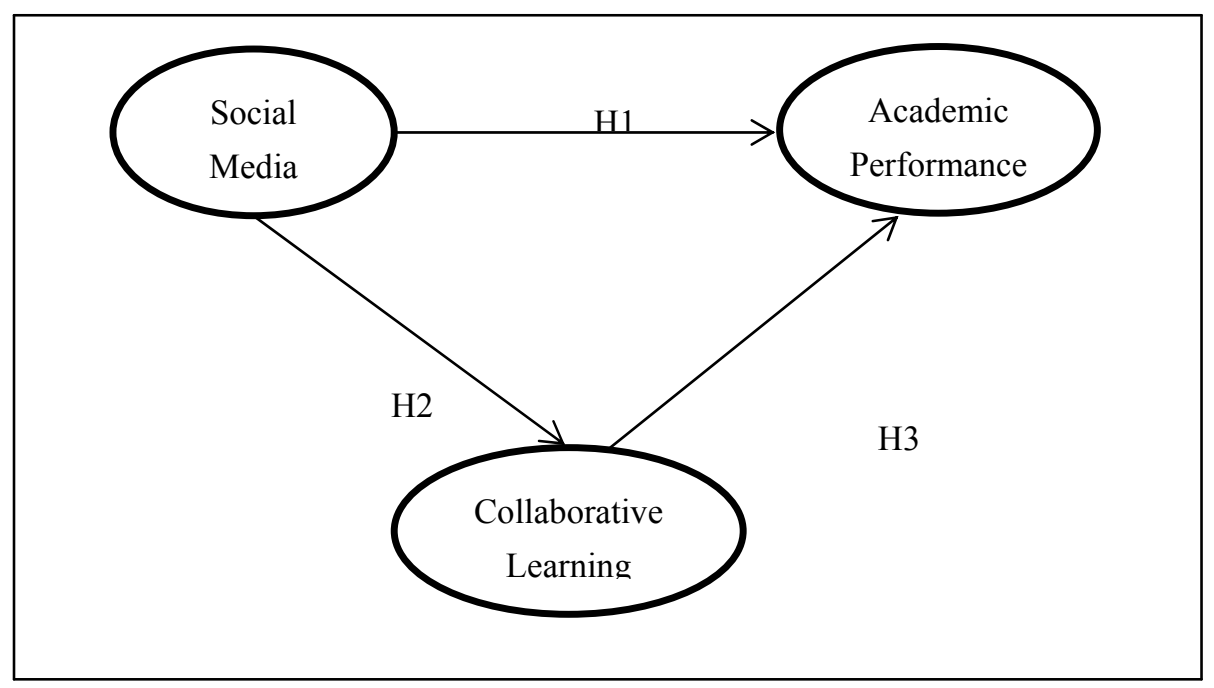

Figure 1. Conceptual framework

\section{Methodology}

The data for this analysis was collected through a survey questionnaire given to 941 postgraduate students during the 2013/2014 academic session. Students were instructed in the survey to offer information about their experiences with the social network tools. In the present research, a quantitative approach was used to test concluded hypotheses empirically. For this survey, the systematic random sampling technique was chosen because it allowed an equal chance amongst the research target population to participate in the research. For modeling, we used AMOS and for analysis, we used LISREL version 8.7.

\subsection{Sample}

The outcomes of the analysis concerning students at Universiti Teknologi Malaysia provide a valuable data set of information about social media, collaborative learning, and academic performance. Faculty of computing was chosen for empirical study as it is the faculty with the highest number of students using social media. Using systematic random sampling technique, participants were chosen randomly from among all postgraduate students studying at Universiti Teknologi Malaysia (UTM). 941 questionnaires were distributed within 2 months and 323 valid responses were collected.

\subsection{Measurement}

A five-point Likert scale (from 1 for strongly disagree to 5 for strongly agree) was applied in this study. The questionnaire was fine-tuned with reference to a study carried out by (Al- rahmi et al., 2013) and the reliability was 0.88. Collaborative learning is considered to be in four scopes: collaboration in learning experience, co-creating the learning experience, freedom of co-creation, and freedom of participation (So \& Brush, 2008). Academic performance is demarcated in three dimensions, including enhanced comprehensiveness of the concept, improved learning experience of the model, and improved understanding of the concept behavior (MacGeorge et al., 2008). 


\section{Results}

\subsection{Correlation Analysis}

The table 1 displays the means, standard deviations of variables and their correlations. As can be seen, the following relationships between the research variables are:

(1) Relationship between social network and collaborative learning: social network is absolutely related to collaborative learning, which shows organizations that utilize social networks demonstrate further capabilities in improving collaborative learning.

(2) Relationship between social network and collaborative learning: Social networks are related to collaborative learning, meaning that participating in more social networks display further capabilities in improving collaborative learning.

(3) Relationship between collaborative learning and academic performance: Collaborative learning is absolutely related to academic performance, which shows that institutions that practice collaborative learning display higher potential in improving learning accomplishment. Correlations can just show the extent of association between constructs. More analysis by structural equation modeling is needed to better comprehend the direct and indirect impacts, and also facilitating outcomes between the constructs.

Table 1. The means, standard deviation and correlation of the study

\begin{tabular}{|c|c|c|c|c|c|c|c|c|c|c|c|}
\hline Variables & 1 & 2 & 3 & 4 & 5 & 6 & 7 & 8 & 9 & 10 & 11 \\
\hline SM1 & .64 & & & & & & & & & & \\
\hline SM2 & .71 & .67 & & & & & & & & & \\
\hline SM3 & .68 & .75 & .59 & & & & & & & & \\
\hline SM4 & .72 & .67 & .71 & .63 & & & & & & & \\
\hline CL1 & .54 & .57 & .66 & .49 & .51 & & & & & & \\
\hline CL2 & .62 & .49 & .47 & .53 & .63 & .57 & & & & & \\
\hline CL3 & .73 & .64 & .48 & .68 & .46 & .43 & .62 & & & & \\
\hline CL4 & .53 & .66 & .55 & .46 & .75 & .49 & .64 & .46 & & & \\
\hline AP1 & .66 & .56 & .74 & .46 & .64 & .72 & .73 & .53 & .79 & & \\
\hline AP2 & .57 & .73 & .55 & .49 & .64 & .62 & .56 & .59 & .62 & .65 & \\
\hline AP3 & .66 & .63 & .47 & .52 & .67 & .69 & .63 & .54 & .56 & .49 & .58 \\
\hline Means & 3.33 & 3.21 & 3.54 & 3.5 & 3.26 & 3.42 & 3.46 & 3.52 & 3.22 & 3.59 & 3.61 \\
\hline SD & .45 & .43 & .47 & .54 & .48 & .62 & .46 & .48 & .53 & .44 & .459 \\
\hline
\end{tabular}

\subsection{Measurement Model}

To test this theoretical model, LISREL 8.7 is used. The flexible interplay between the theory and data characterizes this structural equation model approach, as well as its characteristics of connecting theoretical and empirical knowledge for a better comprehension of the real world (Fornell \& Larcker, 1981). Such studies permits modeling based on both hidden and apparent variables, which are well-matched to the hypothesized model, where most of the signified constructs are concepts of unobservable phenomena.

On top of that, the structural equation modeling (SEM) takes into account mistakes in measurement, variables with numerous indicators, and multiple-group collation. Table 1 shows the means, standard deviations, and correlation coefficient of each research variable to be used as analysis of the significance level of the association that exists between the analyzed constructs. As for the quality measurement of the full sample, the reliability of the constructs is acceptable, as shown in table las the fitting index of measurement of each construct. By considering the factor loading and t-values of the constructs, the convergent validity can be judged. All the constructs of the multi-items are in line with the criterion (t-values greater than 1.96) in support of convergent validity (see Table 3).For the discriminate validity, a number of different tests were conducted on the factor correlations for all the constructs (Anderson \& Gerbing, 1988). 
Table 2. Index of complimentary factors

\begin{tabular}{llll}
\hline Index & SM & CL & AP \\
\hline GFI & .83 & .89 & .86 \\
SRMR & .067 & .053 & .059 \\
RMSEA & .075 & .064 & .071 \\
NNFI & .90 & .94 & .90 \\
CFI & .91 & .94 & .91 \\
$x^{2}$ & 438.4 & 187.6 & 473.5 \\
DF & 138 & 75 & 120 \\
Normed chi-square & 3.17 & 2.5 & 3.94 \\
\hline
\end{tabular}

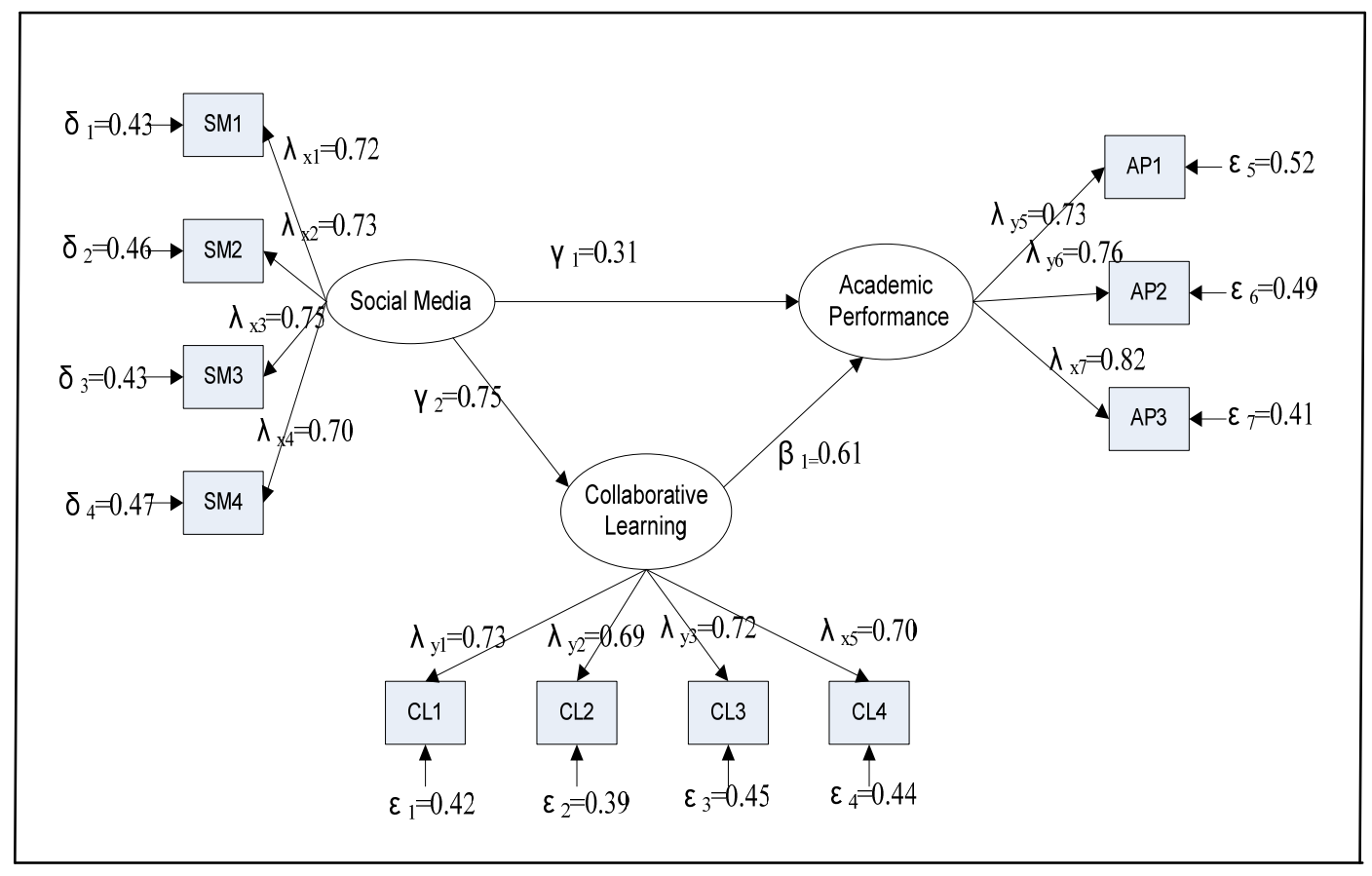

Figure 2. Results for the proposed framework

Table 3. Reliability and convergent validity

\begin{tabular}{ccccc}
\hline Variables & reliability & $\lambda$ & $\varepsilon$ & t-values \\
\hline \multirow{3}{*}{ SM } & & .72 & .43 & 14.21 \\
& \multirow{3}{*}{0.87} & .73 & .46 & 14.55 \\
& & .75 & .43 & 14.18 \\
& & .70 & .47 & 14.03 \\
\cline { 3 - 5 } CL & .73 & .42 & 14.33 \\
& 0.81 & .39 & .39 & 16.86 \\
& & .72 & .45 & 14.78 \\
& & .70 & .44 & 16.12 \\
\cline { 3 - 4 } AP & & .73 & .52 & 13.42 \\
& 0.91 & .76 & .49 & 14.64 \\
& & .82 & .41 & 16.12 \\
\hline
\end{tabular}


As a result of a considerable variation, two constructs were showed as not manifested and hence not fully correlated and consequently discriminate validity was achieved. Hence, after a two-stage analysis, we obtained the outcomes of both convergent validity and discriminate validity. Based on Tables 4 and 5, all t-values showed well convergent validity, and the values of chi-square were greater than 3.84 , which is enough proof for discriminate validity.

\subsection{Structural Model}

To evaluate the strength of the outcomes and constancy of the models, the structural equation modeling of the LISREL 8.7 is employed. Table 6 illustrates the parameter estimates and GFI indicators for the structural model. The results showed that this structure conformed to the data well, $2(41, \mathrm{n}=323)=123.11, \mathrm{p}<.01, \mathrm{CFI}=.94$, $\mathrm{NNFI}=.93, \mathrm{RMSEA}=.052$. The structural model with the standardized coefficients for the investigated sample is highlighted in Table 6. Adequate support for hypothesis 1 (H1) was highlighted by the result observed in Table 6. Social media is substantially and absolutely linked to academic performance, $\gamma 1=0.26, \mathrm{t}(41)=2.67, \mathrm{p}<: 05$. And the numbers in Table 5 and 6 provide support for hypothesis 2 and 3. Social media is substantially and absolutely linked to academic performance, $\gamma 2=75, \mathrm{t}(40)=10.16, \mathrm{p}<.05$. Collaborative learning is substantially and positively linked to academic performance, $\beta 1=61, \mathrm{t}(51)=6.22, \mathrm{p}<.05$.

Table 4. Discriminate validity

\begin{tabular}{cccc}
\hline Model & $\chi 2$ & DF & $\Delta \chi^{2}$ \\
\hline- & 123.11 & 41 & - \\
SM-AP & 208.55 & 40 & $85.44^{*}$ \\
SM-CL & 172.61 & 40 & $49.50^{*}$ \\
CL-AP & 197.29 & 40 & $74.18^{*}$ \\
\hline
\end{tabular}

* Significant at $\Delta \chi>3.84$

Table 5. Goodness of fit analysis

\begin{tabular}{ccccc}
\hline Hypothesis & path & SC & t-values & result \\
\hline $\mathrm{H} 1$ & $\mathrm{SM} \rightarrow \mathrm{AP}(\gamma 1)$ & .31 & 2.1 & Supported \\
$\mathrm{H} 2$ & $\mathrm{SM} \rightarrow \mathrm{CL}(\gamma 2)$ & .75 & 10.16 & Supported \\
$\mathrm{H} 3$ & $\mathrm{CL} \rightarrow \mathrm{AP}(\beta 1)$ & .61 & 6.22 & Supported \\
& $\chi 2(25 \mathrm{df})=121.86$. & $\mathrm{GFI}=.92$ & $\mathrm{CFI}=.94$ & \\
& $\mathrm{Standar} \mathrm{dRMR}=.45$ & $\mathrm{NNFI}=.93$ & $\mathrm{RMSEA}=.72$ & \\
\hline
\end{tabular}

Table 6. Direct and indirect effects

\begin{tabular}{llccc}
\hline Variables & \multicolumn{3}{c}{ Collaborativelearning } & \multicolumn{2}{c}{ Academicperformance } \\
& Effect & t-values & effects & t-values \\
\hline Exogenous & & & & \\
Socialmedia & & & .31 & 2.1 \\
Direct & 75 & 10.16 & .52 & 4.81 \\
Indirect & - & - & .83 & 9.25 \\
Total & & & & \\
\hline Endogenous & & & .61 & 6.22 \\
Collaborativelearning & & & - & - \\
Direct & & .60 & 6.2 \\
Indirect & & & \\
Total & & & & \\
\hline
\end{tabular}


And for the results stated in Table 6 is aim at providing analysis highlighting both direct and indirect effects of the used constructs. After examination, it was discovered that direct effect of social media on collaborative is 0.75 at $\mathrm{t}=2.10$, while there was no indirect effect. And for the direct effect of social media on academic performance is 0.31 at $\mathrm{t}=4.81$, while the indirect effect is 0.52 at $\mathrm{t}=4.81$. Therefore we can see that the indirect effect is greater than the direct effect, and hence collaborative learning here is serving as the mediating variable between social media and academic performance. For higher education to achieved outmost academic performance with social media it is necessary to improve in their collaborative learning.

\section{Discussion}

This research was able to highlight the roles of important variables that have been already treated as separate and independent variables, and thereafter introduced a comprehensive model. This research resulted in a significant and positive relationship between the social media and academic performance, which is in line with findings reported by Alexander (2006) and Nachmias (2002). According to SEM in our results, it has been shown that social media greatly and positively affects collaborative learning. This means the more staff and students uses social media, the more they increase their collaborative learning, and vice versa. This was in agreement with the findings proposed by Gallini and Moely (2003) who find out that the interaction via social media among students and teachers encourages the students to actively collaborate in the class and involve highly in the learning process. The findings also show a relationship between the collaborative learning and academic performance, where the former positively affects the later. This means educational institutions need to provide a more collaborative context if they want to improve the students' academic performance. This collaboration can be among students and between teachers and their learners. Angeli, Valanides and Bonk (2003) also found out that when students collaborate among themselves and with their teachers, their ability to think critically is increased, hence improvement of their academic performance.

Finally, the main theoretical contribution of this research is proposing the collaborative learning as mediating factor between social media and academic performance. It is empirically shown that the relationship between social media and academic performance is a bit significant with a direct effect smaller than indirect effect. As a result, for an organization to achieve optimum academic performance, it must provide the opportunity for collaborative learning through using the social media interactively.

\subsection{Limitations and Future Work}

In this study, we focused on only four constructs of social media. In future, other constructs in social media can be considered in details. There is also need for considering moderator variables like organizational types and culture types in the model. Furthermore, the interactions among the collaborative learning and academic performance can be examined in details; the generalization of sampling is another issue in this research.The data for this study were collected from students of UTM only, and as such the sample size is relatively small which will be a setback in generalization issues.

\subsection{Conclusion}

This research examined the relevancy of social media, and the relationship among collaborative learning and academic performance. In accordance with 323 valid collected responses, the paper implements SEM to test and validate the research hypotheses and framework. The findings suggest that social media is a very important input to academic performance, while the collaborative learning is the mediator. Therefore, social media significantly affects the academic performance, but with the help of collaborative learning, social media's effect can be more significant. Therefore, educational institutions must develop the use of social media in order to improve their students' academic performance.

\section{Acknowledgements}

This material is based upon work supported by Instructional Development Grant (IDG) and Research University Grant (RUG) Universiti Teknologi Malaysia, and the Academy of Sciences for the Development World (TWAS) Research Grant under Vote No. 08216,02J 57, and 10-147 RG/ITC/AS_C; UNESCO FR:3240246311. Any opinions, findings, and conclusions or recommendations expressed in this material are those from the authors and do not necessarily reflect on the views of the Universiti Teknologi Malaysia and the Academy of Sciences for the Development World; also supported by Faculty of Marine, Hudaiadah University, Hudaiada, Yemen.

\section{References}

Abrami, P. C., \& Bures, E. M. (1996). Computer-Supported Collaborative Learning and Distance Education. American Journal of Distance Education, 10(2), 37-42. http://dx.doi.org/10.1080/08923649609526920 
Alexander, B. (2006). Web 2.0: A new wave of innovation for teaching and learning? EDUCAUSE Review, 41(2), $32-44$.

Al-rahmi, W., \& Othman, M. (2013a). The Impact of Social Media use on Academic Performance among university students: A Pilot Study.Journal of information systems research and innovation. Retrieved from http://seminar.utmspace.edu.my/jisri/

Al-rahmi, W., Othman, M., \& Musa, M. (2014).The improvement of students' academic performance by using social media through collaborative learning in Malaysian higher education. Asian Social Science, 10(8).

Angeli, C. et al. (2003). Communication in a web-based conferencing system: The quality of computer-mediated interaction. British Journal of Educational Technology, 34(1), 31-43. http://dx.doi.org/10.1111/1467-8535.00302

Archer, W. et al. (2001). A framework for analyzing critical thinking in computer conferences. Paper presented at the European Conference on Computer-Supported collaborative learning, Maastricht, The Netherlands.

Borstnar, M. K. (2012). Towards Understanding Collaborative Learning in the Social Media Environment. Organizacija, 45(3).

Brainard, J. (2007). Boston College Case Study. Retrieved from http://www.socialtext.net/cases2/index.cgi?boston_college_case_study

Bukvova, H. et al. (2010). What we blog: A qualitative analysis of researchers' weblogs. In Publishing in the networked world: Transforming the nature of communication, 14th international conference on electronic publishing, Helsinki, Finland.

Caldwell, J. E. (2007). Clickers in the large classroom: Current research and beast-practice tips. CBE Life Sciences Education, 6(1), 9-20. http://dx.doi.org/10.1187/cbe.06-12-0205

Chickering, A. W., \& Gamson, Z. F. (1987). Seven principles for good practice in undergraduate education. AAHE Bulletin March, 3-7.

Collins, E., \& Hide, B. (2010). Use and relevance of web 2.0 resources for researchers (pp. 16-18). Paper presented at the International Conference on Electronic Publishing, Helsinki, Finland.

Dabbagh, N., \& Kitsantas, A. (2011). Personal learning environments, social media, and self-regulated learning: A natural formula for connecting formal and informal learning, Internet and Higher Education (in press).

Fornell, C., \& Larcker, D. F. (1981). Evaluating structural equations models with unobservable variables and measurement error. Journal of Marketing Research, 18(1), 39-50. http://dx.doi.org/10.2307/3151312

Greenhow, C., \& Robelia, B. (2009). Informal learning and identity formation in online social networks. Learning, Media and Technology, 34, 119-140. http://dx.doi.org/10.1080/17439880902923580

Gruzd, A. et al. (2011). Imagining twitter as an imagined community. American Behavioural Scientist, 55(10), 1294-1318. http://dx.doi.org/10.1177/0002764211409378

Guthrie, J. T., \& Wigfield, A. (2000). Engagement and motivation in reading. In M. Kamil, \& P. Mosenthal (Eds.), Handbook of reading research (pp. 403-422). Mahwah, NJ: Lawrence Erlbaum.

Hamid, S. et al. (2009). Identifying the use of online social networking in higher education. Same places, different spaces. Proceedings Ascilite Auckland 2009. Retrieved from http://www.ascilite.org.au/conferences /auckland09/procs/hamid-poster.pdf

Hiltz, S. R. et al. (2000). Measuring the importance of collaborative learning for the effectiveness of all: A multi-measure, multi-method approach. Journal of Asynchronous Learning Networks, 4(2), 103-125.

Howland, J. L. et al. (2012). Meaningful Learning with Technology (4th ed.). Boston, Pearson Education Inc.

Janssen, J. et al. (2012) Task-related and Social Regulation During Online Collaborative Learning. Metacognition and Learning, 7(1), 25-43. http://dx.doi.org/10.1007/s11409-010-9061-5

Jmora, M. (2010). collaborative learning experiences using social networks. Electronic Journal of Academic and Special Librarianship, 4(2).

Kaya, T. (2010). CUNY social network mixes scholarship with Facebook-style friendship. Retrieved from http://chronicle.com/blogPost/CUNYSocialNetworkMixes/27266/?sid=wc\&utm_s

Kazmer, M. M. (2007). How do student experiences differ in online LIS programs with and without a resi-dency? The Library Quarterly, 77(4), 359-383. http://dx.doi.org/10.1086/520995 
Kim, H. S. et al. (2008). A Multi-course Collaborative Project: Using Technology to Learn. Journal of Family and Consumer Sciences, 100 (3), 34-41.

Kirkup, G. (2010). Academic blogging: Academic practice and academic identity. London Review of Education, 8(1), 75-84. http://dx.doi.org/10.1080/14748460903557803

Kuh, G. D. et al. (2007). Connecting the dots: Multi-faceted analyses of the relationship between student engagement results from the NSSE, and the institutional practices and conditions that foster student success. Bloomington, IN: Center for Postsecondary Research.

Letierce, J. et al. (2010). Understanding how Twitter is used to spread scientific messages. In Proceedings of the WebSci10: Extending the Frontiers of Society On-Line (pp. 26-27). Raleigh, NC, US.

Liao, S. H. et al. (2007). Knowledge sharing, absorptive capacity and innovation capability: An empirical study on Taiwan's knowledge intensive industries. Journal of Information Science, 33(3), 340. http://dx.doi.org/10.1177/0165551506070739

MacGeorge, E. L. et al. (2008). The influence of learning characteristics on evaluation of audience response technology. Journal of Computing in Higher Education, 19, 25-46. http://dx.doi.org/10.1007/BF03033425

Mack, D. et al. (2007). Reaching students with Facebook: Data and best practices. Electronic Journal of Academic and Special Librarianship, 8(2).

Mason, R., \& Rennie, F. (2008). The E-learning Handbook: Social Networking for Higher Education: Resources for Higher Education (1st ed.). New York: Rout ledge.

Mayer, R. (2008). Designing instruction for constructivist learning. In C. M. Reigeluth (Ed.), Instructional-Design Theories and Models: A New Paradigm of Instructional Theory (p. 2). Hillsdale, N.J: Lawrence Erlbaum Associates.

McGarry, W. (2012). Using Social Media to Enhance Learning through Collaboration in Higher Education: A Case Study. Association's 2012 AAEA Annual Conference, Seattle, Washington.

Minocha, S. (2009). A study on the effective use of social software by further and higher education in the uk to support student learning and engagement. Retrieved from http://www.jisc.ac.uk/whatwedo/projects/ socialsoftware 08

$\mathrm{Na}$ Li. et al. (2012). Using Social Media for Collaborative Learning in Higher Education: A Case Study, ACHI 2012: The Fifth International Conference on Advances in Computer-Human Interactions.

Panitz, T. (1996). A definition of collaborative versus cooperative learning. Retrieved from http://www.londonmet.ac.uk/deliberations/collaborative-learning/panitzpaper.

Rambe, P. (2012). Constructive Disruptions for Effective Collaborative Learning: Navigating the Affordances of Social Media for Meaningful Engagement. The Electronic Journal of e-Learning (EJEL).

Resta, P., \& Laferrière, T. (2007). Technology in support of collaborative learning. Educational Psychology Review, 19(1), 65-83. http://dx.doi.org/10.1007/s10648-007-9042-7

Rowlands, I. et al. (2011). Social media use in the research workflow. Learned Publishing, 24(3), 183. http://dx.doi.org/10.1087/20110306

Rutherford, C. (2010). Using Online Social Media to Support Preservice Student Engagement. MERLOT Journal of Online Learning and Teaching, 6(4).

Ryan, A. M. (2000). Peer groups as a context for the socialization of adolescents' motivation, engagement, and achievement in school. Educational Psychologist, 35, 101-111. http://dx.doi.org/10.1207/S15326985EP3502_4

Safran, C. D., \& Gütl, C. (2007). E-Learning practices and Web 2.0, Proc. International Conference on Iteractive Computer Aided Learning, 1, 1-8.

Siemens, G. (2004). Connectivism: a learning theory for the digital age. Elearnspace everything elearning.

Skemp, R. R. (1071). The Psychology of Learning Mathematics. Middlesex, UK: Penguin.

Slusser, S. R., \& Erickson, R. J. (2006). Group Quizzes: An Extension of the Collaborative Learning Process. Teaching Sociology, 34(3), 249-262. http://dx.doi.org/10.1177/0092055X0603400304

Smith, S. D., \& Caruso, J. B. (2010). The ECAR study of undergraduate students and information technology. EDUCA USE Center for Applied Research (ECAR). 
Thalheimer, W. (2003). The learning benefits of questions (white papers). Somerville, MA: Work Learning Research.

Wesch, M. (2009). From knowledgeable to knowledge-able: Learning in new media environments. Academic commons.com.

Yourstone, S. A. et al. (2008). Classroom questioning with immediate electronic response: Do clickers improve learning? Decision Sciences Journal of Innovative Education, 6(1), $75-88$. http://dx.doi.org/10.1111/j.1540-4609.2007.00166.x

\section{Copyrights}

Copyright for this article is retained by the author, with first publication rights granted to the journal.

This is an open-access article distributed under the terms and conditions of the Creative Commons Attribution license (http://creativecommons.org/licenses/by/3.0/). 